\title{
Effect of altering substrate availability on metabolism and performance during intense exercise
}

\author{
John A. Hawley ${ }^{1}$, Louise M. Burke ${ }^{2}$, Damien J. Angus ${ }^{3}$, Kieran E. Fallon ${ }^{2}$, David T. Martin ${ }^{2}$ \\ and Mark A. Febbraio ${ }^{3}$ \\ ${ }^{1}$ Exercise Metabolism Group, Department of Human Biology \& Movement Science, R.M.I.T. University, Victoria 3083, \\ Australia \\ ${ }^{2}$ Department of Sports Nutrition, Sports Medicine \& Applied Physiology, The Australian Institute of Sport, ACT 2616, \\ Australia \\ ${ }^{3}$ Exercise Physiology and Metabolism Laboratory, Department of Physiology, The University of Melbourne, Victoria 3052, \\ Australia \\ (Received 20 December 1999 - Revised 8 May 2000 - Accepted 17 June 2000)
}

\begin{abstract}
The purpose of this study was to determine the effect of altering substrate availability on metabolism and performance during intense cycling. Seven highly trained men ingested a random order of three isoenergetic meals $90 \mathrm{~min}$ before cycling at $80 \%$ maximal oxygen uptake $\left(\mathrm{VO}_{2 \max }\right.$ ) for $20 \mathrm{~min}$ (about $310 \mathrm{~W}$ ), followed by a $600 \mathrm{~kJ}$ time trial lasting about $30 \mathrm{~min}$. Meals consisted of either $1.2 \mathrm{~g}$ saturated fat $/ \mathrm{kg}$ body mass (BM) with $3500 \mathrm{U}$ heparin intravenously (HIFAT) to elevate circulating plasma free fatty acid (FA) concentration, $2.5 \mathrm{~g}$ carbohydrate $/ \mathrm{kg} \mathrm{BM}(\mathrm{CHO})$ to elevate plasma glucose and insulin concentrations or $2.5 \mathrm{~g}$ carbohydrate $+20 \mathrm{mg}$ nicotinic acid/kg BM (NA) to suppress lipolysis and reduce free FA concentration. HIFAT elevated free FA concentration (HIFAT 1.3 (SEM 0.2), CHO $0 \cdot 2$ (SEM $0 \cdot 1$ ), NA 0.1 (SEM 0.1) mM; $P<0.001$ ), lowered the RER (HIFAT 0.94 (SEM 0.01), CHO 0.97 (SEM 0.01), NA 0.98 (SEM 0.01); $P<0.01$ ) and increased the rate of fat oxidation (HIFAT 24 (SEM 3), CHO 12 (SEM 2), NA 8 (SEM 3) $\mu \mathrm{mol} / \mathrm{kg}$ per min; $P<0.01$ ) during the $20 \mathrm{~min}$ ride. Marked differences in fat availability and fuel utilisation, however, had little effect on performance in the subsequent time trial (HIFAT 320 (SEM 16), CHO 324 (SEM 15), NA 315 (SEM 13) W). We conclude: (1) increased fat availability during intense cycling increases the rate of fat oxidation; but (2) the reduction in the rate of carbohydrate oxidation in the presence of high circulating plasma free FA is unlikely to enhance intense exercise performance lasting about $1 \mathrm{~h}$; (3) substrate selection during intense (about $80 \% \mathrm{VO}_{2 \max }$ ) exercise is dominated by carbohydrate oxidation.
\end{abstract}

Carbohydrate: Cross-over concept: Fat: Nicotinic acid

During continuous, high-intensity exercise performed at about $85 \%$ maximal $\mathrm{O}_{2}$ uptake $\left(\mathrm{VO}_{2 \max }\right)$ and lasting about $1 \mathrm{~h}$, muscle glycogen is the major energy source for muscle (Romijn et al. 1993). At such intensities, the rate of muscle glycogenolysis is rapid (Dyck et al. 1993, 1996) and the concentrations of plasma lactate (Romijn et al. 1995; Hawley et al. 1997) and catecholamines (Kjaer et al. 1991) are 2-3-fold higher compared with moderate intensity (60$70 \% \mathrm{VO}_{2 \max }$ ) exercise. During intense exercise, the rate of appearance of fatty acids (FA) into the plasma are suppressed (Romijn et al. 1993; Sidossis et al. 1997) and net contracting leg FA uptake is reduced (Kjaer et al. 1991), partly because of the failure of FA mobilisation to increase above resting basal levels (Romijn et al. 1993) and also due to insufficient blood flow and albumin delivery to carry FA from the peripheral adipocytes into the systemic circulation (Hodgetts et al. 1991).

In the search for strategies to enhance athletic performance, many studies have investigated a variety of nutritional procedures that increase fat availability and promote FA oxidation (for review see Hawley et al. 1998). In theory, any intervention that elevates the rate of

\footnotetext{
Abbreviations: BM, body mass; CHO, high-carbohydrate meal; FA, fatty acids; HIFAT, high-fat meal plus intravenous heparin; NA, highcarbohydrate meal plus nicotinic acid; $\mathrm{VO}_{2 \max }$, maximal $\mathrm{O}_{2}$ uptake.

* Corresponding author: Dr John A. Hawley, fax +61394678181, email john.hawley@rmit.edu.au
} 
appearance of FA into the plasma above those levels normally observed during moderate-intensity exercise could have a positive effect on exercise capacity by slowing the rate of muscle glycogen depletion (Hawley, 2000). Indeed, FA can be oxidised to a significant extent during intense exercise if they are adequately provided to the muscle (Dyck et al. 1996). Under such conditions, the elevation of plasma free FA concentration by the intravenous infusion of a triacylglycerol emulsion (Dyck et al. 1993, 1996; Odland et al. 1998; Vukovich et al. 1993) or the consumption of a high-fat meal followed by infusion of heparin (Costill et al. 1977; Vukovich et al. 1993) reduces the rate of muscle glycogenolysis compared with either a placebo control trial or when subjects ingested carbohydrate before exercise.

Alternatively, increasing the concentration of free FA in the plasma during moderate to high-intensity exercise may increase FA availability without substantially affecting either substrate utilisation or exercise capacity. This is because during high-intensity exercise carbohydrate flux and oxidation regulate FA oxidation (Coyle et al. 1997; Sidossis et al. 1997; Bergman \& Brooks, 1999) not vice versa (Randle et al. 1963). Accordingly, it has been hypothesised that elevating plasma free FA concentration during high-intensity exercise is unlikely to induce significant shifts in substrate oxidation (from carbohydrate to fat) or effect exercise capacity (Brooks \& Mercier, 1994). However, as recently noted the absence of such an effect has not been determined experimentally (Coyle, 1997).

The aim of the present investigation, therefore, was to determine whether altering the availability of plasma free FA before strenuous exercise would modify the rates of substrate oxidation during a bout of intense cycling and then to examine if such perturbations might affect subsequent time trial performance. In order to increase plasma free FA availability, a high-fat meal plus heparin was administered. Heparin releases the enzyme lipoprotein lipase from endothelial binding sites into the circulation where it (presumably) has better contact with circulating triacylglycerol-rich particles and can exert its action on the hydrolysis of triacylglycerol (Camps et al. 1990). To elevate plasma glucose and insulin concentrations and decrease lipolysis and FA oxidation (Horowitz et al. 1997) carbohydrate was ingested, while we attempted to further suppress lipolysis by feeding nicotinic acid with carbohydrate (Murray et al. 1995). Nicotinic acid decreases lipolysis by causing an inhibition of adenylate cyclase activity and intracellular cAMP, and a resultant decrease in hormone-sensitive lipase activity (Dipalma \& Thayer, 1991).

\section{Methods \\ Subjects}

Seven highly trained cyclists all who had a minimum of 5 years endurance training were recruited to participate in this study, which was approved by the Human Research Ethics Committee's of the Australian Institute of Sport and RMIT University. Their mean age, body mass (BM) and $\mathrm{VO}_{2 \max }$ were 26.4 (SEM 1.7) years, 72.6 (SEM 1.9) kg and $71.2($ SEM $3 \cdot 1) \mathrm{ml} / \mathrm{kg}$ per min respectively. At the time of the investigation subjects were cycling 400 (SEM 53) km/ week in Canberra at an altitude of $588 \mathrm{~m}$. Subjects, who had all participated in previous studies and were familiar with all testing protocols, were fully informed of the nature and possible risks of the investigation before giving their written consent. Each subject completed a medical history including any previous bleeding abnormalities before commencing the experimental trials, and a resting blood sample $(5 \mathrm{ml})$ was taken and analysed for platelet count. All subjects were free of any abnormal clotting characteristics.

\section{Preliminary testing}

On the first visit to the laboratory, each subject performed a maximal, incremental cycle test to exhaustion on an electromagnetically-braked ergometer (Lode Instruments, Groningen, The Netherlands). The test protocol has been described in detail previously (Hawley \& Noakes, 1992). A first principles calibration rig was used to evaluate the accuracy and reliability of this ergometer. Expected power output (W) was within $\pm 2 \%$ actual power output from 200-800 W when the pedal frequency was 90-140 rpm. During the maximal test and the 20 min experimental ride, subjects inspired air through a two-way Hans Rudolf valve attached to a custom built automated Douglas bag gas analysis system (Australian Institute of Sport, ACT, Australia) which incorporated $\mathrm{O}_{2}$ and $\mathrm{CO}_{2}$ analysers (Ametek N-22 electrochemical $\mathrm{O}_{2}$ sensor, model S3A, and Ametek P-61B infrared $\mathrm{CO}_{2}$ sensor; Applied Electrochemistry, Ametek Instruments, Pittsburgh, PA, USA) and two Tissot gasometers (Warren E. Collins Inc., Braintree, MA, USA) interfaced to an IBM personal computer by optical rotary encoders (RS 341-597; Berne, Switzerland) that calculated the rate of $\mathrm{O}_{2}$ consumption, $\mathrm{CO}_{2}$ production, minute ventilation and the RER every $30 \mathrm{~s}$ from conventional equations (Robergs \& Roberts, 2000). Before each maximal test and all the subsequently described trials, the analysers were calibrated with commercially available gases of known $\mathrm{O}_{2}$ and $\mathrm{CO}_{2}$ content. Before and after the study, an automated high-capacity calibrator for opencircuit indirect calorimetry was used to simultaneously check the gas analysers, volume device and software of the custom built system (Gore et al. 1997). This device can calibrate to the high ventilation volumes (about $100 \mathrm{l} / \mathrm{min}$ ) measured when well-trained athletes work for sustained periods at high $\left(80-85 \% \mathrm{VO}_{2 \max }\right)$ exercise intensities.

$\mathrm{VO}_{2 \max }$ was defined as the highest $\mathrm{O}_{2}$ uptake a subject attained during two consecutive $30 \mathrm{~s}$ sampling periods. The results of this maximal test were used to determine the power output that corresponded to $80 \%$ of each subject's $\mathrm{VO}_{2 \max }$ to be used during the 20 min experimental rides.

Training and nutritional status of the subjects were controlled for the day before each experimental trial in order to regulate muscle and liver glycogen stores. All subjects reported to the laboratory $24 \mathrm{~h}$ before a trial, immediately upon completion of an easy $60 \mathrm{~min}$ cycle. Subjects rode the same route and at the same intensity before each trial. They were then provided with a standard 
diet of $209 \mathrm{~kJ} / \mathrm{kg} \mathrm{BM}$, composed of $63 \%$ energy as carbohydrate $(8 \mathrm{~g} / \mathrm{kg} \mathrm{BM}), 20 \%$ as fat, and $17 \%$ as protein, to be consumed that day. Subjects refrained from any further activity for this period. Such standardisation of the subject's training and diet has previously been shown to result in similar pre-exercise muscle glycogen stores (Flynn et al. 1987).

\section{Experimental trials}

Each subject completed a random order of three experimental trials: a fat-feeding (HIFAT) trial, a carbohydratefeeding trial $(\mathrm{CHO})$ and a trial where carbohydrate plus nicotinic acid (NA) was ingested. All subjects plus one investigator who supervised the performance rides (described subsequently) were blinded to the order of the trials. On the morning of an experiment subjects reported to the laboratory between 06.00 and 07.00 hours after an overnight fast. As blood was to be repeatedly sampled after a test meal and during exercise, a cannula (20G; Terumo, Tokyo, Japan) was inserted into an antecubital vein of one arm, and a resting sample $(10 \mathrm{ml})$ was taken. Following each blood sample, the cannula was flushed with $5 \mathrm{ml}$ $\mathrm{NaCl}(9 \mathrm{~g} / \mathrm{l})$ to keep the vein patent. Subjects then ingested one of the three test meals. For the HIFAT trial, subjects were required to consume a meal of $1.2 \mathrm{~g}$ saturated fat $/ \mathrm{kg}$ $\mathrm{BM}$. For the $\mathrm{CHO}$ and NA trials subjects consumed an isoenergetic carbohydrate meal $(2.5 \mathrm{~g} / \mathrm{kg} \mathrm{BM})$. The nutritional analyses of the drinks are given in Table 1 . Immediately after finishing their test meal for that experiment, subjects rested for $90 \mathrm{~min}$ before exercise. Blood samples $(10 \mathrm{ml})$ were taken 30 and $60 \mathrm{~min}$ after ingestion of a test meal, and 1 min before subjects began the experimental ride. In the HIFAT trial heparin was administered intravenously $1 \mathrm{~h}(2000 \mathrm{U})$ and $75 \mathrm{~min}$ $(500 \mathrm{U})$ after the test meal, and $1 \mathrm{~min}(500 \mathrm{U})$ prior to the commencement of the experimental ride. In an attempt to further suppress adipocyte lipolysis during the NA trial, subjects ingested $10 \mathrm{mg}$ nicotinic acid/kg BM (RhonePoulenc Rorer, Victoria, Australia) $1 \mathrm{~h}$ after finishing the test meal, and $5 \mathrm{mg} / \mathrm{kg} \mathrm{BM} 15 \mathrm{~min}$ prior to the experimental ride. Intermittent administration of NA was chosen as this has been shown to reduce any negative circulatory effects of the drug experienced when a single bolus dose is given (Pernow et al. 1967; Pernow \& Saltin, 1971). At the same time points that subjects ingested nicotinic acid, they ingested placebo tablets containing about $500 \mathrm{mg}$ sucrose during the HIFAT and $\mathrm{CHO}$ experiments. At the same time point that subjects received an intravenous infusion of heparin, they were given a sham infusion of saline during the NA and $\mathrm{CHO}$ experiments.

Exactly 90 min after ingestion of a test meal, the subject mounted the ergometer and began a standardised $5 \mathrm{~min}$ incremental warm-up. Upon completion of the warm-up the workload was immediately adjusted to $80 \% \mathrm{VO}_{2 \max }$ and they began 20 min continuous cycling. During this ride, blood samples $(10 \mathrm{ml})$ were taken after 10 and $20 \mathrm{~min}$. Expired gas was collected throughout the last $10 \mathrm{~min}$ of the ride. A 20 min time period was chosen for measurements of metabolism because previous studies have shown that the majority of carbohydrate 'sparing' after elevated free FA concentration occurs during the first 15-20 min intense exercise (Dyck et al. 1993, 1996; Vukovich et al. 1993). Upon completion of this ride, subjects were allowed a standardised ( $3 \mathrm{~min}$ ) rest while they remained seated on the ergometer. During this time, they consumed either placebo tablets during the HIFAT and CHO trials, or $5 \mathrm{mg}$ nicotinic $\mathrm{acid} / \mathrm{kg}$ during the NA trial. During this rest period, a further $500 \mathrm{U}$ heparin was administered to subjects during the HIFAT trial. After exactly 3 min, subjects commenced a performance ride of $600 \mathrm{~kJ}$ which they were instructed to complete 'as fast as possible'. In a pilot study, we determined that a $600 \mathrm{~kJ}$ time-trial took our trained subjects about $30 \mathrm{~min}$ to complete at an intensity of about 80-82\% $\mathrm{VO}_{2 \max }$ (JA Hawley, unpublished results). When combined with the $20 \mathrm{~min}$ experimental ride, cyclists would be exercising for a total time of 50-60 min at about $80 \%$ $\mathrm{VO}_{2 \max }$. After subjects had completed $50 \%$ of the work, a blood sample $(10 \mathrm{ml})$ was taken with a final sample drawn during the last $60 \mathrm{~s}$ of the ride. Throughout the performance ride, subjects were informed of their progress at $50 \mathrm{~kJ}$ intervals, and when they had completed $550 \mathrm{~kJ}$, they were given feedback every $10 \mathrm{~kJ}$ until they finished the ride.

During the 20 min experimental rides, subjective ratings of perceived exertion were obtained after 10, 15 and 20 min using the modified Borg scale (Borg, 1975). During the performance ride, ratings of perceived exertion were obtained upon completion of every $100 \mathrm{~kJ}$. Heart rates during the experimental trials were measured by telemetry (Polar Sports Tester; Polar Electro OY, Kempele, Finland).

Table 1. Composition of the pre-exercise test meals ${ }^{\star}$

\begin{tabular}{|c|c|c|}
\hline & High-fat meal & High-carbohydrate meal \\
\hline Ingredient & $\begin{array}{l}\text { Full cream }(350 \mathrm{~g} \text { fat } / \mathrm{kg}) 215 \mathrm{~g} \\
\text { Low-energy chocolate topping } 50 \mathrm{~g} \\
\text { Full-cream milk } 100 \mathrm{ml}\end{array}$ & $\begin{array}{l}\text { Polyjoule }^{\mathrm{TM}} \dagger 85 \mathrm{~g} \\
\text { Regular chocolate topping } 70 \mathrm{~g} \\
\text { Skimmed milk } 400 \mathrm{ml} \\
\text { Sustagen Sport powder }{ }^{\mathrm{TM}} \ddagger 55 \mathrm{~g}\end{array}$ \\
\hline \multicolumn{3}{|l|}{ Analyses§ } \\
\hline Energy (kJ) & 3458 & 3473 \\
\hline Fat $(\mathrm{g})$ & 83 (89 \% energy) & 2 (3 \% energy) \\
\hline Carbohydrate (g) & 16 (7\% energy) & 173 (82\% energy) \\
\hline Protein $(\mathrm{g})$ & 9 (4\% energy) & 32 (15\% energy) \\
\hline
\end{tabular}

* Based on a $70 \mathrm{~kg}$ subject.

† Baxter Health Care Proprietary Limited, Old Toongabbie, New South Wales, Australia.

‡ Bristol Myers, Ryalamere, New South Wales, Australia.

$\S$ Source: NUTTAB Database, Australian Department of Community Services and Health, 1995. 


\section{Analytical techniques}

Upon sampling, about $5 \mathrm{ml}$ whole blood was placed into a tube containing fluoride heparin, mixed and spun at $800 \mathrm{~g}$ for $2 \mathrm{~min}$. The resultant plasma was stored at $-80^{\circ} \mathrm{C}$ for later analyses of glucose and lactate using automated analyses (ABL 615 Radiometer, Copenhagen, Denmark) and insulin by radioimmunoassay (Incstar, Stillwater, MN, USA). Blood for adrenaline, noradrenaline and free FA determination was placed in tubes containing ethylene glycol-bis( $\beta$-aminoethyl ether)- $N, N, N^{\prime}, N^{\prime}$-tetraacetic acid and GSH and spun in a centrifuge at $4^{\circ} \mathrm{C}$ for $15 \mathrm{~min}$ at 900 g. The plasma was stored at $-80^{\circ} \mathrm{C}$ until analysed. Plasma adrenaline and noradrenaline were analysed using a single isotope $\left[{ }^{3} \mathrm{H}\right]$-radioenzymatic assay system (TRK995; Amersham, Bucks., UK) and plasma free FA was analysed using an enzymatic colorimetric method (Wako, NEFAC code 279-75409, Tokyo, Japan). A further $2 \mathrm{ml}$ whole blood were placed in a tube containing lithium heparin, mixed, and spun down for $2 \mathrm{~min}$. A $500 \mu \mathrm{l}$ portion of plasma was transferred into a tube containing $500 \mu \mathrm{l}$ icecold $3 \mathrm{M}-\mathrm{HClO}_{4}$, mixed and spun in a centrifuge at $900 \mathrm{~g}$ at $0^{\circ} \mathrm{C}$ for $2 \mathrm{~min}$. An $800 \mu \mathrm{l}$ portion of the resultant supernatant was then added to a tube containing $200 \mu \mathrm{l} 6 \mathrm{M}$ $\mathrm{KOH}$ mixed and spun in a centrifuge at $0^{\circ} \mathrm{C}$ for $2 \mathrm{~min}$. The supernatant was stored at $-80^{\circ} \mathrm{C}$ until analysed for glycerol using enzymatic analysis with fluorometric detection (Pinter et al. 1967).

Whole-body rates of carbohydrate and fat oxidation $(\mathrm{g} /$ $\mathrm{min})$ were calculated throughout the last $10 \mathrm{~min}$ of each experimental ride from the rates of $\mathrm{CO}_{2}$ production and $\mathrm{O}_{2}$ consumption using the non-protein RER values, according to the following equations (Peronnet \& Masicotte, 1991):

$$
\begin{aligned}
\text { CHO oxidation }= & 4.585 \mathrm{VCO}_{2}(1 / \mathrm{min}) \\
& -3.226 \mathrm{VO}_{2}(1 / \mathrm{min}),
\end{aligned}
$$

and

$$
\text { fat oxidation } \begin{aligned}
= & 1.695 \mathrm{VO}_{2}(\mathrm{l} / \mathrm{min}) \\
& -1.701 \mathrm{VCO}_{2}(\mathrm{l} / \mathrm{min}),
\end{aligned}
$$

where $\mathrm{VCO}_{2}$ is the rate of $\mathrm{CO}_{2}$ production and $\mathrm{VO}_{2}$ is the rate of $\mathrm{O}_{2}$ consumption. These equations are based on the assumption that $\mathrm{VO}_{2}$ and $\mathrm{VCO}_{2}$ accurately reflect tissue $\mathrm{O}_{2}$ consumption and $\mathrm{CO}_{2}$ production. In well-trained subjects similar to those employed in the current investigation, indirect calorimetry has been shown to be a valid method for quantifying rates of substrate oxidation during strenuous exercise at about $85 \% \mathrm{VO}_{2 \max }$ (Romijn et al. 1992). Rates of FA oxidation $(\mu \mathrm{mol} / \mathrm{kg}$ per min) were determined by converting the rate of triacylglycerol oxidation $(\mathrm{g} / \mathrm{kg}$ per $\mathrm{min}$ ) to its molar equivalent assuming the average molecular mass of human triacylglycerol to be $855.3 \mathrm{~g} /$ mol and multiplying the molar rate of triacylglycerol oxidation by three, because each molecule contains $3 \mathrm{mmol}$ FA. Rates of carbohydrate oxidation ( $\mu \mathrm{mol} / \mathrm{kg}$ per min) were determined by converting the rate of carbohydrate oxidation $(\mathrm{g} / \mathrm{min})$ to its molar equivalent assuming $6 \mathrm{~mol}$ $\mathrm{O}_{2}$ are consumed and $6 \mathrm{~mol} \mathrm{CO}_{2}$ produced for each mol (180 g) oxidised.

\section{Statistical analyses}

Data from the three trials were compared using a two-factor (treatment and time) ANOVA with repeated measures. Simple main effect analyses and Neumann-Keul post-hoc tests were undertaken when ANOVA revealed a significant interaction. Total carbohydrate and fat oxidation between trials, and time-trial performances were compared using a one-way ANOVA with treatment as the main factor and, where appropriate, with Neumann-Keul post-hoc test. Significant differences were accepted when $P<0.05$ and all data are reported as mean values with standard errors of the means.

\section{Results}

\section{Dietary control}

Standardisation of each subject's diet was achieved: subjects consumed 577 (SEM 12) (CHO), 579 (SEM 12) (NA) and 575 (SEM 12) (HIFAT) g carbohydrate (8.0 (SEM $0 \cdot 2$ ) (CHO), $8 \cdot 0$ (SEM 0.1) (NA) and 7.9 (SEM 0.2) (HIFAT) $\mathrm{g} / \mathrm{kg} \mathrm{BM}$ ) for the $24 \mathrm{~h}$ prior to each trial. As intended, the total energy intake was the same (CHO 15.2 (SEM 0.3), NA $15 \cdot 2($ SEM $0 \cdot 3)$ and HIFAT $14 \cdot 8$ (SEM 0.4) MJ).

\section{Metabolic data}

Table 2 displays the metabolic data collected during the three

\begin{tabular}{|c|c|c|c|c|c|c|c|c|c|c|c|c|c|c|}
\hline \multirow[b]{2}{*}{ Treatment } & \multicolumn{2}{|c|}{$\mathrm{VO}_{2}(1 / \min )$} & \multicolumn{2}{|c|}{$\mathrm{VCO}_{2}(\mathrm{l} / \mathrm{min})$} & \multicolumn{2}{|c|}{$\mathrm{V}_{\mathrm{E}}(\mathrm{l} / \mathrm{min})$} & \multicolumn{2}{|c|}{ RER } & \multicolumn{2}{|c|}{ Energy (J/kg per min) } & \multicolumn{2}{|c|}{$\begin{array}{c}\mathrm{CHO}_{\text {ox }} \\
(\mu \mathrm{mol} / \mathrm{kg} \text { per min })\end{array}$} & \multicolumn{2}{|c|}{$\begin{array}{c}\text { Fat }_{\mathrm{ox}} \\
(\mu \mathrm{mol} / \mathrm{kg} \text { per } \min )\end{array}$} \\
\hline & Mean & SEM & Mean & SEM & Mean & $\overline{\text { SEM }}$ & Mean & SEM & Mean & SEM & Mean & SEM & Mean & SEM \\
\hline $\mathrm{CHO}$ & $4 \cdot 15$ & 0.12 & 4.01 & 0.11 & 91.0 & 3.4 & 0.97 & 0.01 & 1203 & 30 & 354 & 10 & $11 \cdot 8$ & 1.6 \\
\hline NA & $4 \cdot 15$ & 0.14 & 4.05 & 0.13 & $99 \cdot 3^{*}$ & $4 \cdot 8$ & 0.98 & 0.01 & 1210 & 30 & 368 & 14 & $8 \cdot 1$ & 2.7 \\
\hline HIFAT & $4 \cdot 19$ & 0.12 & 3.93 & 0.11 & 90.9 & $2 \cdot 3$ & $0.94 †$ & 0.01 & 1205 & 25 & $312 \ddagger$ & 8 & $24.0 \ddagger$ & $3 \cdot 2$ \\
\hline
\end{tabular}
20 min experimental rides. As intended, the rate of $\mathrm{O}_{2}$

Table 2. Metabolic data measured during $20 \mathrm{~min}$ of intense cycling for $20 \mathrm{~min}$ at 80 (SEM 1) \% maximal oxygen consumption§ (Mean values with standard errors of the means for seven subjects)

$\mathrm{VO}_{2}, \mathrm{O}_{2}$ uptake; $\mathrm{VCO}_{2}, \mathrm{CO}_{2}$ production; $\mathrm{V}_{\mathrm{E}}$, ventilation; $\mathrm{CHO}_{\mathrm{ox}}$, rate of carbohydrate oxidation; $\mathrm{FAT}$ ox , rate of fat oxidation; CHO, high-carbohydrate meal; $\mathrm{NA}$, highcarbohydrate meal plus nicotinic acid; HIFAT, high-fat meal plus intravenous heparin.

Mean value was significantly different from $\mathrm{CHO}$ and HIFAT: ${ }^{*} P<0.05$; mean value was significantly different from $\mathrm{CHO}$ and $\mathrm{NA}$ : ${ }^{\dagger} P=0.002$; mean values were significantly different from $\mathrm{CHO}$ and $\mathrm{NA}:{ }^{\ddagger} P=0.002$.

$\S$ For details of treatments and procedures see Table 1 and p. 831. 
consumption averaged 80 (SEM 1) \% of the subjects' $\mathrm{VO}_{2 \max }$ and was not different between trials. RER values were lower after fat + heparin administration compared with the other dietary treatments (HIFAT 0.94 (SEM 0.01), CHO 0.97 (SEM 0.01 ) and NA 0.98 (SEM 0.01); $P=0.002$ ). Accordingly, the mean rate of fat oxidation was greater in HIFAT (24 (SEM 3) $\mu \mathrm{mol} / \mathrm{kg}$ per min) compared with either CHO (12 (SEM 2) $\mu \mathrm{mol} / \mathrm{kg}$ per min, $P<0.01$ ) or NA (8 (SEM 3$) \mu \mathrm{mol} / \mathrm{kg}$ per min, $P=0.01)$, while the rate of carbohydrate oxidation was concomitantly lower (HIFAT 312 (SEM 8), CHO 354 (SEM 10 ) and NA 368 (SEM 14) $\mu \mathrm{mol} / \mathrm{kg}$ per min, $P=0 \cdot 01$ ). As a result there was a 'sparing' of carbohydrate in the HIFAT trial compared with the other dietary treatments (HIFAT 81 (SEM 3), CHO 92 (SEM 3) and NA 96 (SEM 4) g/20 min, $P=0 \cdot 01$ ). This 'sparing' meant that the contribution to total energy from carbohydrate was reduced from 90 (SEM 1) \% (CHO) and 93 (SEM $2 \%$ (NA) to 79 (SEM 3) \% in HIFAT $(P<0.001)$. NA elevated the ventilation rate (at STPD) compared with both CHO and HIFAT (NA 99.3 (SEM 4.8), CHO 91.0 (SEM 3.4) and HIFAT 90.9 (SEM 2.3) 1/min; $P<$ $0 \cdot 01$ ), yet despite this higher rate of ventilation there were no differences in either the subjects' heat rates (CHO 165 (SEM 3), NA 165 (SEM 3), HIFAT 164 (SEM 3) beats/min) or ratings of perceived exertion (CHO 13.0 (SEM 0.5), NA 13.8 (SEM $0 \cdot 6)$, HIFAT 12.7 (SEM 0.3)) between treatments.

\section{Plasma glucose, insulin and lactate concentrations}

Fig. 1 displays the plasma glucose, insulin and lactate concentrations for the three dietary treatments. Resting values for these three variables were similar. After the CHO meal, glucose concentration increased slightly to $5 \cdot 7$ (SEM 0.5) mM, but was not different to either HIFAT or NA at any time point before exercise. In contrast, plasma insulin concentrations were rapidly elevated 30 min after ingestion of both $\mathrm{CHO}$ and NA compared with HIFAT (CHO 390 (SEM 51) and NA 289 (SEM 58) v. HIFAT 82 (SEM 1) $\mathrm{pmol} / \mathrm{l} ; P<0.0001$ ) and remained significantly higher throughout the $90 \mathrm{~min}$ pre-exercise period. Although lactate concentrations were similar after ingestion of the three test meals, they tended to be lower after HIFAT compared with either $\mathrm{CHO}$ or NA although such differences were not statistically significant.

Plasma glucose concentration rose steadily throughout the experimental ride so that after $20 \mathrm{~min}$ it had increased from about $4.5 \mathrm{mM}$ to 5.3 (SEM 0.3), 5.6 (SEM 0.4) and 6.0 (SEM $0 \cdot 2$ ) $\mathrm{mm}$ for $\mathrm{CHO}$, NA and HIFAT respectively (Fig. $1, P<$ $0 \cdot 0001)$. In contrast, plasma insulin concentrations decreased rapidly after the first $10 \mathrm{~min}$ of the experimental ride during both CHO and NA (from 279 (SEM 36) and 179 (SEM 17) to about $60 \mathrm{pmol} / \mathrm{l} ; P<0.0001)$ where they remained for the rest of the ride (Fig. 1). As would be expected with the onset of the time trial, plasma lactate concentration increased such that compared with the start of the experimental ride, there was a significant interaction of time $\times$ treatment for all three conditions for both 10 and 20 min time points (Fig. 1; $P<$ $0.05)$. Plasma lactate concentrations remained steady at between 4.5 and $5.5 \mathrm{mmol} / \mathrm{l}$ for the duration of the experimental ride for both $\mathrm{CHO}$ and HIFAT conditions. However, plasma lactate concentrations in NA were higher at both the $10 \mathrm{~min}$ (NA 6.5 (SEM 1.1) v. CHO 4.7 (SEM 0.8) and
HIFAT 4.4 (SEM 0.8) $\mathrm{mM} ; P<0.001$ ) and $20 \mathrm{~min}$ (NA 8.1 (SEM 1.6) $v$. CHO 5.5 (SEM 1.0) and HIFAT 5.3 (SEM 1.0) $\mathrm{mmol} / \mathrm{l} ; P<0.001$ ) time points (Fig. 1). Although there was a modest rise in plasma lactate concentration during the experimental ride (from 6.5 (SEM 1.1) to $8 \cdot 1$ (SEM 1.6) $\mathrm{mmol} / \mathrm{l}$ ) during NA, this increase was not significant.

The performance ride resulted in a modest hyperglycaemia such that at the end of the time trial, plasma glucose concentration had risen to between 6.1 and $6.8 \mathrm{mM}$ for all three treatments (Fig. 1). However, such rises in glucose concentration were not different to those values observed at the end of the experimental ride. Plasma insulin concentrations remained relatively constant throughout the time trial and were similar for all three treatments at the end of the time trial (about $7 \mu \mathrm{U} / \mathrm{ml}$ ). Plasma lactate concentrations rose from about $9.0 \mathrm{mM}$ halfway through the performance ride to about 11-12 $\mathrm{mM}$ at the end of $600 \mathrm{~kJ}$. This rise was likely due to the riding strategy of most subjects who employed a sustained 'sprint finish' during the last 120$150 \mathrm{~s}$ of the time trial.

\section{Plasma free fatty acids and glycerol concentrations}

Resting concentrations of plasma free FA and glycerol were similar for all three treatments (Fig. 2). As intended, HIFAT resulted in a significant increase in fat availability so that $75 \mathrm{~min}$ after ingestion, plasma free FA concentration had risen from 0.40 (SEM 0.03) to 1.31 (SEM 0.15) mM $(P<0.0001)$ compared with a slight decline for the corresponding time period for $\mathrm{CHO}$ and NA. Rises in plasma glycerol concentrations were more modest and were not statistically significant during the $90 \mathrm{~min}$ prior to exercise (Fig. 2).

Plasma free FA concentration remained elevated throughout the experimental ride and for the duration of the subsequent time trial after HIFAT compared with either CHO or NA $(P<0.0001$, Fig. 2$)$. Indeed, even at the end of the time trial, plasma free FA concentrations were higher for HIFAT than the other treatments (HIFAT 0.82 (SEM 0.12 ) v. CHO 0.16 (SEM 0.03) and NA 0.14 (SEM 0.04) mM; $P<0.0001)$. There were no differences in plasma free FA concentration at any time between $\mathrm{CHO}$ and NA. Plasma glycerol concentrations rose progressively with the onset of exercise and were significantly higher compared with the start of exercise after $10 \mathrm{~min}$ in HIFAT and after $20 \mathrm{~min}$ in CHO and NA (Fig. 2). Thereafter, they continued to increase so that by the end of the time trial they were 0.40 (SEM 0.02) (HIFAT), 0.19 (SEM 0.01) (CHO) and 0.15 (SEM 0.01 ) (NA) mM. At all exercise sample points, plasma glycerol concentration was significantly higher after HIFAT than either $\mathrm{CHO}$ or NA $(P<0.0001)$. There were no differences in plasma glycerol concentration at any time point between $\mathrm{CHO}$ and NA.

\section{Plasma catecholamines}

Plasma adrenaline and noradrenaline concentrations are shown in Table 3. There were no differences in resting values between all three treatments for adrenaline and noradrenaline. Although both plasma adrenaline and noradrenaline increased from rest during the $20 \mathrm{~min}$ 

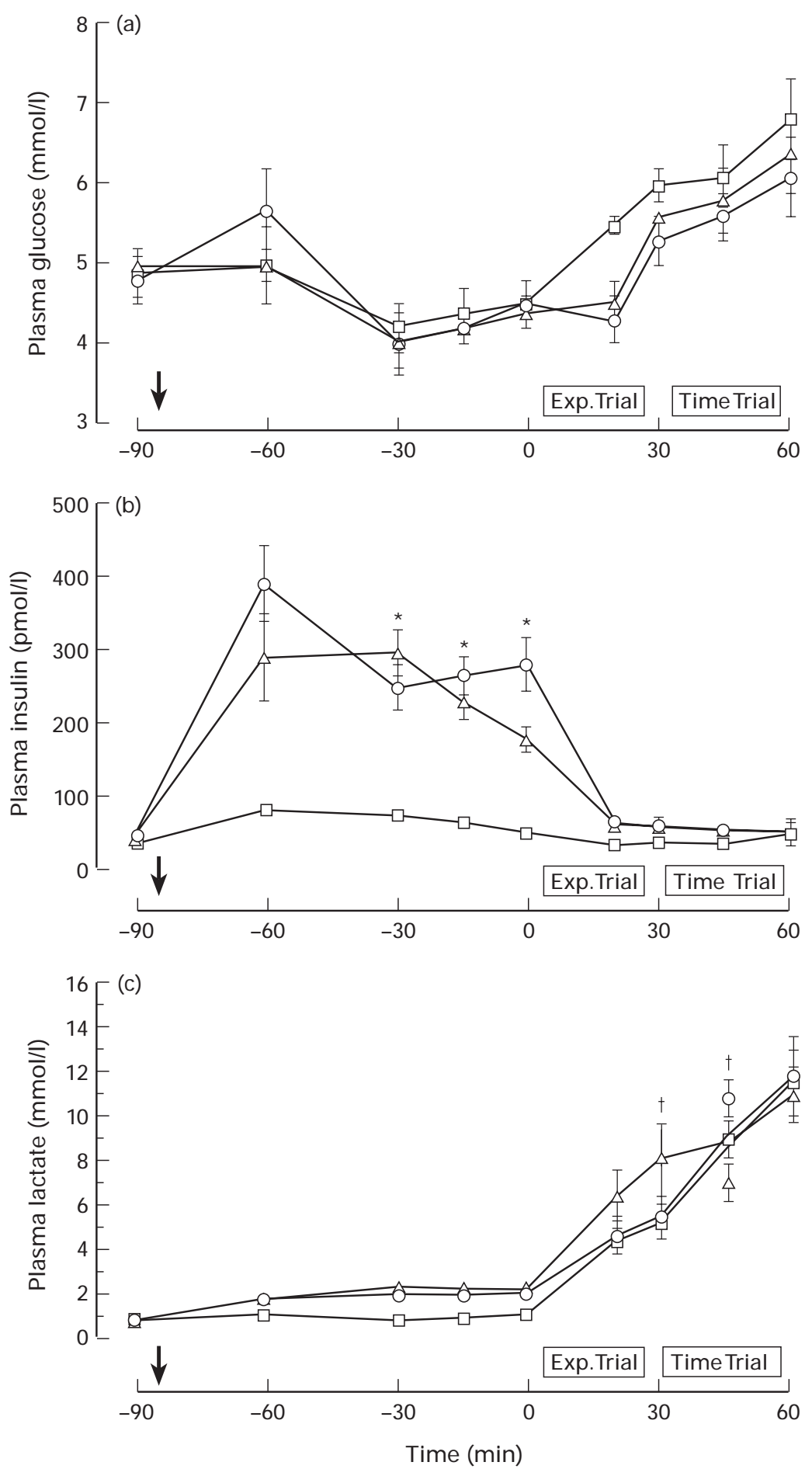

Fig. 1. (a) Plasma glucose, (b) insulin and (c) lactate concentrations during the experimental (Exp) and time trials. Values are means for seven subjects with standard errors of the means shown by vertical bars. For details of treatments and procedures see Table 1 and p. 831. Test meals were ingested 90 min before commencing a 20 min ride at about $80 \%$ maximal $\mathrm{O}_{2}$ uptake (308 (SEM 12) W), immediately followed by a $600 \mathrm{~kJ}$ time trial. $\mathrm{O}, \mathrm{CHO}(2.6 \mathrm{~g}$ carbohydrate $/ \mathrm{kg}) ; \nabla \mathrm{CHO}+\mathrm{NA}(2.6 \mathrm{~g} \mathrm{CHO}+$ $20 \mathrm{mg}$ nicotinic acid $/ \mathrm{kg}) ; \square$, HIFAT $(1.2 \mathrm{~g}$ saturated fat $/ \mathrm{kg}$ with $3500 \mathrm{U}$ heparin intravenously. $\downarrow$, Time of feeding. Mean values were significantly different from HIFAT: ${ }^{*} P<0.001$; mean values were significantly different from $\mathrm{CHO}$ and HIFAT: $\dagger P<$ 0.05 . 

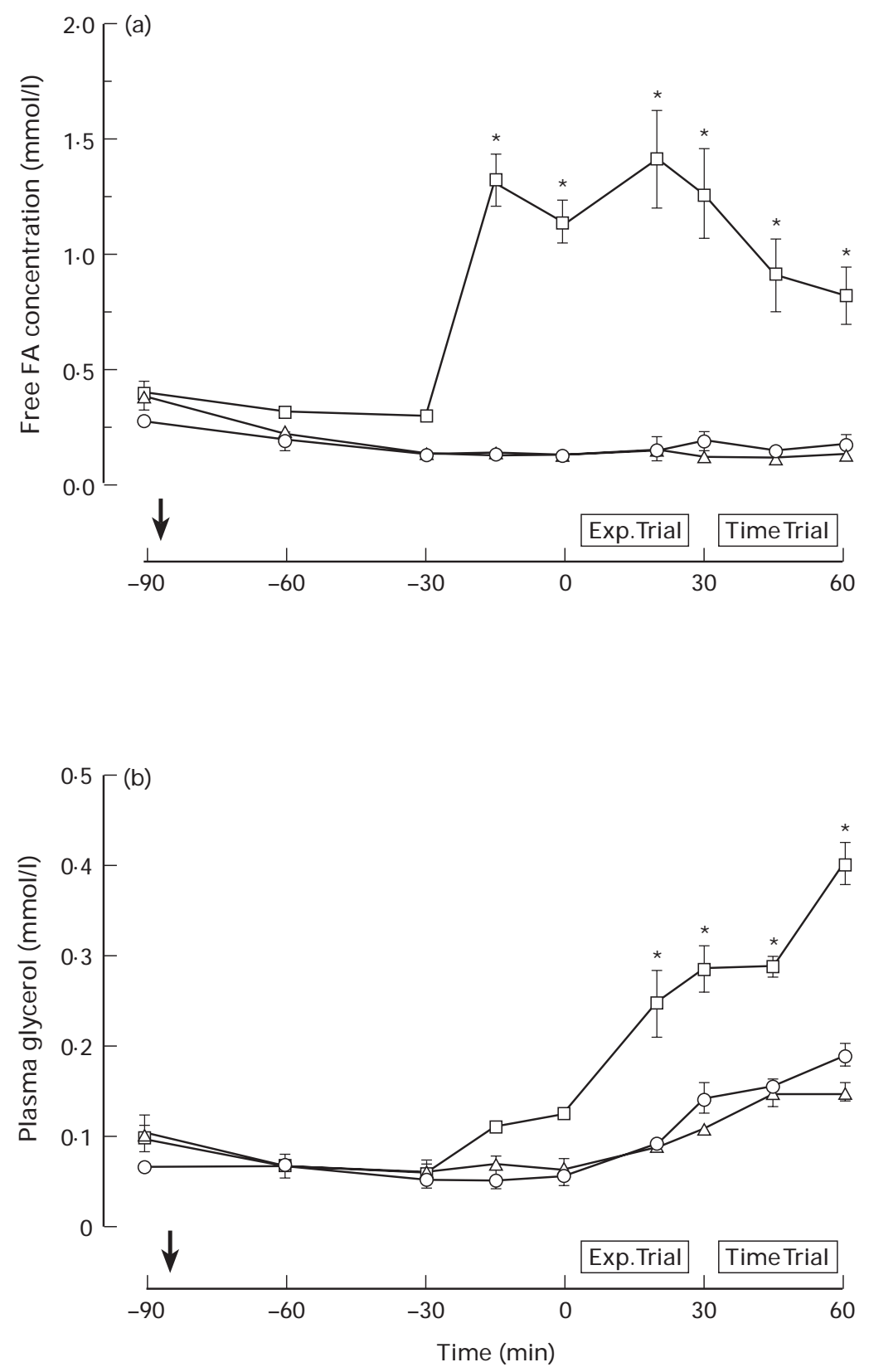

Fig. 2. (a) Plasma free fatty acids (FA) and (b) glycerol concentrations during the experimental (Exp) and time trials. Values are means for seven subjects with standard errors of the means shown by vertical bars. For details of treatments and procedures see Table 1 and p. 831. Test meals were ingested 90 min before commencing a 20 min ride at about $80 \%$ maximal $\mathrm{O}_{2}$ uptake (308 (SEM 12) W), immediately followed by a $600 \mathrm{~kJ}$ time trial. $\mathrm{O}, \mathrm{CHO}(2.6 \mathrm{~g}$ carbohydrate/kg); $\nabla, \mathrm{CHO}+\mathrm{NA}(2.6 \mathrm{~g} \mathrm{CHO}+20 \mathrm{mg}$ nicotinic acid $/ \mathrm{kg}) ; \square$, HIFAT $(1.2 \mathrm{~g}$ saturated fat $/ \mathrm{kg}$ with $3500 \mathrm{U}$ heparin intravenously). $\downarrow$, denotes time of feeding. Mean values were significantly different from $\mathrm{CHO}$ and $\mathrm{NA}$; ${ }^{*} P<0.001$.

experimental ride for all three dietary conditions $(P<$ 0.05), there was no main treatment effect.

Time, power output, ratings of perceived exertion and heart rate during the time trial

The time taken to complete the time trial following the experimental ride was not different between experimental conditions (CHO 31.3, NA 32.1, and HIFAT $31.7 \mathrm{~min}$ ).
Neither was there any difference for the time taken for any $100 \mathrm{~kJ}$ segments of the ride between trials. Accordingly, the average power output (CHO 324 (SEM 15), NA 315 (SEM 13), HIFAT 320 (SEM 16) W) and heart rate (CHO 174 (SEM 3), NA 172 (SEM 2), HIFAT 175 (SEM 3) beats/ min) sustained for the duration of the time trial were similar. Ratings of perceived exertion rose steadily during all three time trials from 14 (SEM 1) units after the first $100 \mathrm{~kJ}$ to 19 (SEM 1) units at the end of the rides. There 
Table 3. Effects of pre-exercise feedings on plasma catecholamine concentration $\ddagger$

(Mean values with standard errors of the means for seven subjects)

\begin{tabular}{|c|c|c|c|c|c|c|c|c|}
\hline \multirow[b]{3}{*}{ Treatment } & \multicolumn{4}{|c|}{ Adrenaline $(\mathrm{nmol} / \mathrm{l})$} & \multicolumn{4}{|c|}{ Noradrenaline $(\mathrm{nmol} / \mathrm{l})$} \\
\hline & \multicolumn{2}{|c|}{ Rest } & \multicolumn{2}{|c|}{ Exercise§ } & \multicolumn{2}{|c|}{ Rest } & \multicolumn{2}{|c|}{ Exercise§ } \\
\hline & Mean & SEM & Mean & SEM & Mean & SEM & Mean & SEM \\
\hline $\mathrm{CHO}$ & 0.53 & 0.10 & $1.30^{*}$ & 0.14 & 1.52 & 0.56 & $11 \cdot 30 \dagger$ & 1.43 \\
\hline NA & 0.57 & 0.15 & $1.97^{\star}$ & 0.52 & 1.47 & 0.37 & $13.31 \dagger$ & $2 \cdot 32$ \\
\hline HIFAT & 0.56 & 0.16 & $1.13^{*}$ & 0.18 & 1.22 & 0.22 & $9 \cdot 61 \dagger$ & 1.08 \\
\hline
\end{tabular}

$\mathrm{CHO}$, high-carbohydrate meal; NA, high-carbohydrate meal plus nicotinic acid; HIFAT, high-fat meal plus intravenous heparin.

Mean values were significantly different from rest: ${ }^{*} P<0.05, \dagger P<0.0001$.

‡ For details of treatments and procedures see Table 1 and p. 831.

$\S$ Exercise sample was taken $20 \mathrm{~min}$ from the start of the experimental ride at $80 \%$ maximal $\mathrm{O}_{2}$ uptake (308 (SEM 12) W).

were no differences in the ratings of perceived exertion between trials at any time point. Likewise, the loss in BM was similar for all conditions (CHO $1 \cdot 2$ (SEM 0.1), NA $1 \cdot 1$ (SEM $0 \cdot 1)$ and HIFAT $1 \cdot 1($ SEM $0 \cdot 1) \mathrm{kg}$ ).

\section{Discussion}

The first finding of the present study was that the ingestion of isoenergetic fat and $\mathrm{CHO}$ meals $1 \mathrm{~h}$ before exercise resulted in dramatic changes in plasma substrate concentrations (Figs. 1 and 2) and marked differences in the rates of substrate oxidation during intense cycling. We deliberately chose ingestion of test meals rather than intravenous infusion of Intralipid or glucose as we wished to elevate circulating metabolite concentrations and induce changes in the regulatory plasma hormones that result from oral administration. Furthermore, a fat meal composed predominantly of saturated FA rather than unsaturated FA was chosen as the saturation of FA has been reported to have little effect on the subsequent decrease in muscle glycogen utilisation during exercise (Vukovich et al. 1993). As intended, ingestion of the fat meal resulted in higher plasma free FA concentrations immediately before and throughout intense exercise, with $\mathrm{CHO}$ ingestion effectively eliminating any rise in plasma free FA concentration both before and during the subsequent exercise bouts (Fig. 1). Horowitz et al. (1997) have previously reported that pre-exercise $\mathrm{CHO}$ ingestion which results in a small (about $20 \mu \mathrm{U} / \mathrm{ml}$ ) elevation in plasma insulin concentration reduces FA oxidation during subsequent exercise.

Contrary to our expectations, there was no additive effect of co-ingesting nicotinic acid (about $1400 \mathrm{mg}$ ) with the $\mathrm{CHO}$ meal with regard to suppression of plasma free FA concentration. This finding contrasts with the results of Murray et al. (1995) who reported that the ingestion of a carbohydrate-electrolyte solution plus nicotinic acid (about $330 \mathrm{mg}$ ), or water plus nicotinic acid both resulted in lower circulating plasma free FA concentrations during submaximal (about $70 \% \mathrm{VO}_{2 \max }$ ) cycling, compared with the ingestion of carbohydrate alone. Such a discrepancy is difficult to explain in that inhibition of lipolysis by nicotinic acid has been reported to be maximal at a plasma concentration of about 1 umol/l (Marcus et al. 1989), a level far below the plasma nicotinic acid concentration observed in the subjects of Murray et al. (1995). Indeed, based solely on the results of the investigation by Murray et al. (1995) we decided not to include a nicotinic acid plus placebo (water) treatment in the current study.

We specifically wished to determine the effects of altering FA availability in competitive athletes exercising at the highest work rates they could sustain for about $1 \mathrm{~h}$, as most (Okano et al. 1996, 1998; Pitsiladis et al. 1999) but not all (Whitley et al. 1998) previous investigations that have utilised a variety of pre-exercise meals to increase FA availability and oxidation have used moderately-trained subjects cycling for prolonged $(>90 \mathrm{~min})$ periods at moderate intensities $\left(60-70 \% \mathrm{VO}_{2 \max }\right)$. Accordingly, we chose a 20 min experimental period during which pulmonary gas exchange measures were taken, followed immediately by a time trial lasting about $30 \mathrm{~min}$ in which the average power output sustained by subjects was similar to the first $20 \mathrm{~min}$ of the ride (about 310-320 W). Hence, the total exercise time was $50-55 \mathrm{~min}$ at about $80 \% \mathrm{VO}_{2 \max }$. More to the point, most of the glycogen 'sparing' has been shown to occur early in exercise (Dyck et al. 1993, 1996; Vukovich et al. 1993) yet still result in a performance enhancement during the later stages of intense work (Spriet et al. 1992). We found a significant reduction in carbohydrate oxidation during intense exercise when plasma free FA concentration was elevated almost fourfold by HIFAT (Table 1). However, an RER value of 0.94 during HIFAT still represents an $80 \%$ contribution from carbohydrate to total energy. On the assumption that the majority of the carbohydrate 'sparing' in the HIFAT trial compared with either $\mathrm{CHO}$ or NA was from muscle glycogen, it would only represent a $10 \%$ reduction in the contribution to total energy from carbohydrate. Our data are in excellent agreement with the $12 \%$ reduction in muscle glycogen utilisation estimated by Romijn et al. (1995) in well-trained cyclists exercising for $20 \mathrm{~min}$ at about $83 \% \quad \mathrm{VO}_{2 \max }$ after a lipid-heparin infusion that elevated plasma FA concentration to $>1.5 \mathrm{mM}$. It is difficult to extrapolate the magnitude of a glycogen 'sparing' effect into a meaningful performance change. However, using the original data of Spriet et al. (1992) it can be calculated that it would take a $20 \%$ reduction in glycogenolysis (about $20 \mathrm{mmol} / \mathrm{kg}$ wet mass) to increase sustainable power output during cycling at $80 \% \mathrm{VO}_{2 \max }$ by about $1.5 \%$ (see Hopkins et al. 1999).

Our results showing a dominance of exercise intensity over dietary manipulation and substrate availability in determining the choice of fuel by the working muscle are consistent with those of others that have used moderateintensity exercise (Whitley et al. 1998; Bergman \& Brooks, 1999). Whitley et al. (1998) studied well-trained cyclists during prolonged moderate intensity exercise $4 \mathrm{~h}$ after ingesting either high-fat or high-carbohydrate meals. Although blood glucose, insulin and free FA concentrations differed before exercise as a result of the different meals, substrate selection during exercise was similar and was dominated by carbohydrate oxidation. Others have also reported that substrate utilisation was not affected by prior diet during moderate intensity exercise in either untrained or trained subjects (Bergman \& Brooks, 1999; Pitsiladis et al. 1999). Taken collectively, these results suggest that at 
the exercise intensities at which most athletes train and compete, they are dependent on carbohydrate oxidation for energy, regardless of prior dietary patterns. Accordingly, the finding that high-intensity cycling performance was similar between all dietary treatments in the current investigation was, perhaps, not surprising as the work rates $\left(>310-320 \mathrm{~W}, 80-85 \% \mathrm{VO}_{2 \max }\right)$ sustained by our subjects for almost $1 \mathrm{~h}$ resulted in high rates of total carbohydrate oxidation and glycolytic flux. Indeed, the only study to find an increase in exercise capacity with fat feeding was that of Pitsiladis et al. (1999). These workers reported that cycling time to exhaustion was prolonged (from 118 to $128 \mathrm{~min}$ ) when their trained subjects ingested a high-fat (90\% energy) $v$. a high-carbohydrate (70\% energy) meal $4 \mathrm{~h}$ prior to exercise. As there were no differences in total carbohydrate oxidation for the first $90 \mathrm{~min}$ of exercise between trials (383 v. $362 \mathrm{~g}$ for the carbohydrate and fat meals respectively), it is difficult to explain a metabolic basis for the prolonged cycling time.

The effects of nicotinic acid administration per se on exercise performance have been investigated previously, with conflicting results. For example, Bergstrom et al. (1969) found no difference in cycling time to exhaustion after nicotinic acid administration even though muscle glycogen utilisation was $33 \%$ greater, arterial lactate concentrations elevated, and plasma free FA concentration lower compared with a control trial. Furthermore, Murray et al. (1995) found no differences in performance during high-intensity cycling (which followed $2 \mathrm{~h}$ submaximal exercise) after ingestion of carbohydrate, carbohydrate plus nicotinic acid, or water plus nicotinic acid. Interestingly, these workers hypothesised that feeding a combination of carbohydrate plus nicotinic acid would result in a greater reliance and oxidation of carbohydrate during intense exercise which might result in a concomitant improvement in performance. Such a hypothesis was based on previous observations that there is a strong relationship ( $r$ 0.94) between the rate of carbohydrate oxidation and power production during intense cycling (Neufer et al. 1987).

A third finding of the present study was that the coingestion of $20 \mathrm{mg}$ nicotinic acid/ $\mathrm{kg} \mathrm{BM}$ with the $\mathrm{CHO}$ meal resulted in significantly higher plasma lactate concentrations and rates of ventilation than when either carbohydrate or fat meals were ingested alone. Some (Bergstrom et al. 1969) but not all (Carlson et al. 1963) studies have reported elevations in lactate concentration with nicotinic acid administration in response to a standard submaximal exercise task when compared with either a glucose feedings or a fasted control group. However, to the best of our knowledge the present study is the first to find an elevation in ventilation during intense exercise in response to nicotinic acid feedings. Such a finding is difficult to explain in light of the similar values measured for both the rate of $\mathrm{O}_{2}$ consumption and, more importantly, the rate of $\mathrm{CO}_{2}$ production during all three experimental rides.

In conclusion, the results of the current investigation show that compared with the consumption of an isoenergetic carbohydrate meal, the ingestion of a high-fat meal (plus heparin administration) significantly increased subsequent FA availability and altered the patterns of substrate utilisation during intense exercise. However, the reduction in the rate of carbohydrate oxidation in the presence of high circulating plasma free FA had little effect on the performance of a $30 \mathrm{~min}$ time trial, which followed $20 \mathrm{~min}$ intense exercise. At the exercise intensities sustained by competitive athletes during training and competition, it is likely that the decrease in carbohydrate utilisation after a fat feeding is inadequate to contribute to a performance enhancement, as substrate selection during such intense exercise is dominated by carbohydrate oxidation.

\section{Acknowledgements}

This study was supported by an RMIT Faculty of Biomedical and Health Science \& Nursing Research grant to J. A. Hawley, and a grant from the Sports Science and Sports Medicine Centre of the Australian Institute of Sport. We wish to thank the subjects for their excellent cooperation.

\section{References}

Bergman BC \& Brooks GA (1999) Respiratory gas-exchange ratios during graded exercise in fed and fasted trained and untrained men. Journal of Applied Physiology 86, 479-487.

Bergstrom J, Hultman E, Jorfeldt L, Pernow B \& Wahren J (1969) Effect of nicotinic acid on physical working capacity and on metabolism of muscle glycogen in man. Journal of Applied Physiology 26, 170-176.

Borg G (1975) Simple rating method for estimation of perceived exertion. In Physical Work and Effort, pp. 39-46 [G Borg, editors]. New York: Pergamon.

Brooks GA \& Mercier J (1994) Balance of carbohydrate and lipid utilization during exercise: the "crossover" concept. Journal of Applied Physiology 76, 2253-2261.

Camps L, Reina M \& Lobera M (1990) Lipoprotein lipase: cellular origin and functional distribution. American Journal of Physiology 258, C673-C681.

Carlson LA, Havel RJ, Ekelund LG \& Holmgren A (1963) Effect of nicotinic acid on the turnover rate and oxidation of the free fatty acids of plasma in man during exercise. Metabolism Clinical Experiment 12, 837-845.

Costill DL, Coyle E, Dalsky G, Evans W, Fink W \& Hoopes D (1977) Effects of elevated plasma FFA and insulin on muscle glycogen usage during exercise. Journal of Applied Physiology 43, 695-699.

Coyle EF (1997) Fuels for sport performance. In Perspectives in Exercise Science and Sports Medicine. Volume 10. Optimising Sport Performance, pp. 105-129 [DR Lamb and R Murray, editors]. Carmel, IN: Cooper Publishing Group.

Coyle EF, Jeukendrup AE, Wagenmakers AJM \& Saris WHM (1997) Fatty acid oxidation is directly regulated by carbohydrate metabolism during exercise. American Journal of Physiology 273, E268-E275.

Dipalma JR \& Thayer WS (1991) Use of niacin as a drug. Annual Review of Nutrition 11, 169-187.

Dyck DJ, Peters SJ, Wendling PS, Chesley A, Hultman E \& Spriet LL (1996) Regulation of muscle glycogen phosphorylase activity during intense aerobic cycling with elevated FFA. American Journal of Physiology 270, E116-E125.

Dyck DJ, Putman CT, Heigenhauser GJF, Hultman E \& Spriet LL (1993) Regulation of fat-carbohydrate interaction in skeletal 
muscle during intense aerobic cycling. American Journal of Physiology 265, E852-E859.

Flynn MG, Costill DL, Hawley JA, Fink WJ, Neufer PD, Fielding RA \& Sleeper MD (1987) Influence of selected carbohydrate drinks on cycling performance and glycogen use. Medicine \& Science in Sports \& Exercise 19, 37-40.

Gore CJ, Catcheside PG, French SN, Bennett JM \& Laforgia DJ (1997) Automated $\mathrm{VO}_{2 \max }$ calibrator for open circuit indirect calorimetry systems. Medicine \& Science in Sports \& Exercise 29, 1095-1103.

Hawley JA (2000) Nutritional strategies to enhance fat oxidation during aerobic exercise. In Clinical Sports Nutrition, pp. 428-454 [LM Burke and V Deakin, editors]. Sydney: McGraw-Hill.

Hawley JA, Brouns F \& Jeukendrup AE (1998) Strategies to enhance fat utilisation during exercise. Sports Medicine 25, $241-257$.

Hawley JA \& Noakes TD (1992) Peak sustained power output predicts $\mathrm{VO}_{2 \max }$ and performance time in trained cyclists. European Journal of Applied Physiology 65, 79-83.

Hawley JA, Palmer GS \& Noakes TD (1997) Effects of 3 days of carbohydrate supplementation on muscle glycogen content and utilisation during a 1-h cycling performance. European Journal of Applied Physiology 75, 407-412.

Hodgetts V, Coppack SW, Frayn KN \& Hockaday TDR (1991) Factors controlling fat mobilization from human subcutaneous adipose tissue during exercise. Journal of Applied Physiology 71, 445-451.

Hopkins WG, Burke LM \& Hawley JA (1999) Design and analysis of research on sport performance enhancement. Medicine \& Science in Sports \& Exercise 31, 472-485.

Horowitz JF, Mora-Rodriguez R, Byerley LO \& Coyle EF (1997) Lipolytic suppression following carbohydrate ingestion limits fat oxidation during exercise. American Journal of Physiology 273, E768-E775.

Kjaer MB, Kiens B, Hargreaves M \& Richter EA (1991) Influence of active muscle mass on glucose homeostasis during exercise in humans. Journal of Applied Physiology 71, 552-557.

Marcus C, Sonnenfeld T, Karpe B, Bolme P \& Arner P (1989) Inhibition of lipolysis by agents acting via adenylate cyclase in fat cells from infants and adults. Pediatric Research 26, 255259.

Murray R, Bartolli WP, Eddy DE \& Horn MK (1995) Physiological and performance responses to nicotinic-acid ingestion during exercise. Medicine \& Science in Sports \& Exercise 27, 1057-1062.

Neufer PD, Costill DL, Flynn MG, Kirwan JP, Mitchell JB \& Houmard J (1987) Improvements in exercise performance: effects of carbohydrate feedings and diet. Journal of Applied Physiology 62, 983-988.

Odland LM, Heigenhauser GJ, Hollidge-horvat MG \& Spriet LL (1998) Effects of increased fat availability on fat-carbohydrate interaction during prolonged exercise in men. American Journal of Physiology 274, R894-R902.

Okano G, Sato Y \& Murata Y (1998) Effect of elevated blood FFA levels on endurance performance after a single fat meal ingestion. Medicine \& Science in Sports \& Exercise 30, 763768 .
Okano G, Sato Y, Takumi M \& Sugawara M (1996) Effect of 4-h pre-exercise high carbohydrate and high fat meal ingestion on endurance performance and metabolism. International Journal of Sports Medicine 17, 530-534.

Pernow B, Havel RJ \& Jennings DB (1967) The second wind phenomenon in McArdles syndrome. Acta Medica Scandinavia Suppl. 472, 294-307.

Pernow B \& Saltin B (1971) Availability of substrates and capacity for prolonged heavy exercise in man. Journal of Applied Physiology 31, 416-422.

Peronnet F \& Massicotte D (1991) Table of nonprotein respiratory quotient: an update. Canadian Journal of Sports Science 16, 23-29.

Pinter JK, Hayashi JA \& Watson JA (1967) Enzymatic assay of glycerol, dihydroxyacetone and glyceraldehyde. Archives of Biochemistry Biophysics 121, 404.

Pitsiladis YP, Smith I \& Maughan RJ (1999) Increased fat availability enhances the capacity of trained individuals to perform prolonged exercise. Medicine \& Science in Sports \& Exercise 31, 1570-1579.

Randle P, Garland P, Hales C \& Newsholme E (1963) The glucose fatty acid cycle. Its role in insulin sensitivity and the metabolic disturbances of diabetes mellitus. Lancet 1, 785-789.

Robergs RA \& Roberts SO (2000) Fundamental Principles of Exercise Physiology, pp. 67. Boston, MA: McGraw Hill.

Romijn JA, Coyle EF, Hibbert J \& Wolfe RR (1992) Comparison of indirect calorimetry and a new breath ${ }^{13} \mathrm{C} /{ }^{12} \mathrm{C}$ ratio method during strenuous exercise. American Journal of Physiology 263, E64-E71.

Romijn JA, Coyle EF, Sidossis LS, Gastaldelli A, Horowitz JF, Endert E \& Wolfe RR (1993) Regulation of endogenous fat and carbohydrate metabolism in relation to exercise intensity and duration. American Journal of Physiology 265, E380-E391.

Romijn JA, Coyle EF, Sidossis LS, Zhang XJ \& Wolfe RR (1995) Relationship between fatty acid delivery and fatty acid oxidation during strenuous exercise. Journal of Applied Physiology 79, 1939-1945.

Sidossis LS, Gastaldelli A, Klein S \& Wolfe RR (1997) Regulation of plasma fatty acid oxidation during low- and high-intensity exercise. American Journal of Physiology 272, E1065-E1070.

Spriet LL, Maclean DA, Dyck DJ, Hultman E, Cederblad G \& Graham TE (1992) Caffeine ingestion and muscle metabolism during prolonged exercise in humans. American Journal of Physiology 262, E891-E898.

Vukovich MD, Costill DL, Hickey MS, Trappe SW, Cole KJ \& Fink WJ (1993) Effect of fat emulsion, infusion and fat feeding on muscle glycogen utilization during cycle exercise. Journal of Applied Physiology 75, 1513-1518.

Whitley HA, Humphreys SM, Campbell IT, Keegan MA, Jayanetti TD, Sperry DA, Maclaren DP, Reilly T \& Frayn KN (1998) Metabolic and performance responses during endurance exercise after high-fat and high-carbohydrate meals. Journal of Applied Physiology 85, 418-424. 